\title{
PEMILIHAN VARIABEL PENENTU PERAWATAN PERMESINAN KAPAL UNTUK MENAIKKAN KEANDALAN KAPAL TNI AD
}

\author{
${ }^{1}$ DIDIET SUDIRO RESOBOWO, ${ }^{2}$ KETUT BUDA A, ${ }^{3} \mathrm{AAB}$. DINARIYANA \\ ${ }^{1}$ Institute Technology of Sepuluh November, Department of Marine, Surabaya \\ ${ }^{2}$ Institute Technology of Sepuluh November, Department of Marine, Surabaya \\ ${ }^{3}$ Institute Technology of Sepuluh November, Department of Marine, Surabaya \\ E-mail: ${ }^{1}$ didietsudiro@ gmail.com, ${ }^{2}$ ketutbuda@its.ac.id, ${ }^{3}$ dinar@ its.ac.id
}

\begin{abstract}
Penelitian ini dilakukan untuk memilih beberapa variabel yang berpengaruh terhadap perawatan permesinan kapal dengan menggunakan Analytic Hierarchy Process (AHP). Dalam sistem manajemen perawatan terdiri dari 8 variabel yaitu :Cost, Availability, SDM, Reliability, Safety, Operasional, Jumlah dan Jenis Kapal dan Karakteristik kapal. Pemilihan kedelapan variabel tersebut dilaksanakan dengan menyebar kuisioner. Kuesioner disebarkan kepada 30 Anak buah Kapal baik perwira, bintara dan tamtama untuk dipilih variabel yang bisa digunakan dalam manajemen perawatan dalam perawatan kapal- kapal militer. Dari hasil kuesioner dihasilkan 7 variabel. Langkah selanjutnya menggunakan Expert Choice yang menghasilkan 4 variabel yang berpengaruh yaitu SDM $=0.247$, Cost $=0.222$, Availability $=0.197$ dan Reliability $=0.104$.
\end{abstract}

Keywords: Perawatan Permesinan Kapal, Anak Buah Kapal, AHP, Expert Choice

\section{INTRODUCTION}

Filosofi dasar dari sebuah konsep perawatan adalah bagaimana melakukan kegiatan untuk menjamin suatu aset fisik dapat bekerja secara kontinyu sesuai fungsi yang diinginkan. Dengan kata lain yaitu, apa yang harus dilakukan untuk mempertahankan fungsi dari sebuah sistem atau komponen dalam kurun waktu tertentu dan pada kondisi operasi tertentu. Kemampuan suatu item untuk bekerja dengan baik sesuai fungsi yang diinginkan inilah yang harus dapat dijamin oleh konsep perawatan yang akan dipilih nantinya. Tingkat kemampuan ini biasanya diwakili oleh suatu nilai probabilitas yang disebut Indeks Keandalan (Reliability Index).

Secara teori, konsep perawatan yang tepat adalah konsep perawatan yang dapat menghasilkan indeks keandalan tinggi pada sistem, sehingga sistem dapat optimal beroperasi sesuai fungsinya.Perkembangan konep perawatan saat ini pada generasi ke empat hal ini masih diperlukan pengembangan suatu konsep di bidang perawatan karena ada kendala yang dihadapi,seperti system control yang kompleks dampak terhadap lingkungan,dampak terhadap keselamatan, tingginya biaya perawatan atau permasalahan yang lain Pada generasi keempat ini ditandai dengan ramah lingkungan dari suatu system keandalan (reliability) atau peningkatan (prepared) operasional system alutsista yang

Jurnal Kajian Teknik Mesin

Vol. 1 No. 2 
dirawat dari kegiatan aktivitas perawatan.tersebut. Secara umum fungsi perawatan adalah mengembalikan atau menjaga kondisi obyek yang dirawat dengan sedemikian rupa sehingga mendekati kondisi awal obyek tersebut saat dioperasikan (Billinton, 1992).

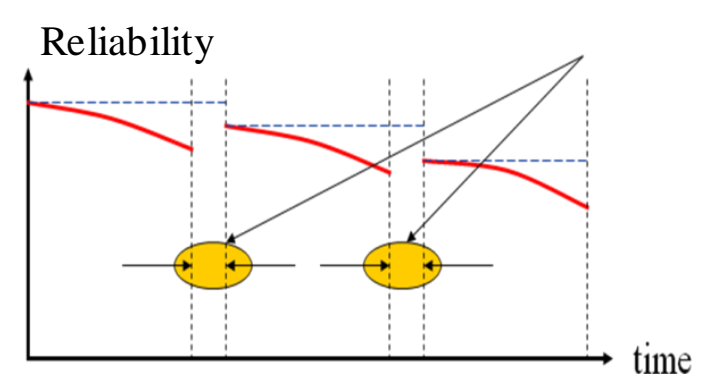

Gambar 1. Fungsi Perawatan

Berdasarkan gambar 2 diatas apabila system komponen semakin sering dilakukan perawatan sehingga kondisi system/komponen keandalannya akan stabil karena semakin banyak komponen itu dirawat,berarti semakin berkurang jam produktifnya sehingga Costnya naik, namun sebaliknya semakin sedikit waktu perawatan maka jam produktifnya semakin bertambah sehingga costnya kecil, Waktu perawatan sangat berpengaruh pada waktu produktifnya.Dalam hal ini perlu dilakukan suatu penelitian thd manajemen perawatan system permesinan dikapal yang tepat agar tidak mengganggu jam produktifnya / jam operasinya dan biaya,Secara signifikan tujuan utama dari perawatan adalah menjaga dan memperbaiki keandalan dari system dan kelancaran produksi atau operasi sehingga dapat mencegah kegagalan system, juga untuk mengembalikan fungsi system (Ketut Buda A. 2003)

Rekomendasi dari pihak manajemen selaku decision maker dalam kebijaksanaan perawatan sangat berpengaruh pada kebijaksanaan perawatan dalam pengalaman, safety dan kondisi operasi, ketersediaan dana dan tenaga kerja, jadwal operasi kapal, Reliability, Availability serta manajemen dan jaminan kualitas, karena sesuai dorongan dan aplikasi standart internasional ISO 9000 sehingga mendapat perhatian yang lebih baik dari tahun sebelumnya,pada akhirnya pemeliharaan dititik beratkan pada komponen kritis (critical Componen),yang dapat mempengaruhi keandalan system (Lahar Baliwangi 2006)

Perawatan permesinan dibagi menjadi dua yaitu :Pre ventive dan Corrective Maintenance. Metode perawatan yang dilakukan dengan memelihara suatu peralatan agar dapat bekerja dengan baik (Prevent from Failure ) disebut Preventive Maintenance. Metode Corrective Maintenance adalah suatu metode perawatan dengan melakukan perbaikan agar suatu peralatan dapat berfungsi kembali,setelah terjadi kerusakan, hal ini cara pemeliharaannya mirip pada Kapal-kapal militer mengingat tidak tepatnya waktu pemeliharaan dan keterbatasan anggaran pemeliharaan.

Jenis-jenis Perawatan dan Pemeliharaan menurut Gopalakrishnan dan Benerjee yaitu: 
1.Routine Maintenance :Kegiatan inspeksi terhadap peralatan secara rutin dan diadakan penggantian suku cadang yang selalu disiapkan apabila kerusakan ter jadi dengan cirri-ciri sebagai berikut:

a) Biaya kerusakan relative murah bila terjadi kerusakan.

b) Tenaga SDM terlalu lama menganggur,karena kesulitan sudah dapat diatasi.

c) Umur peralatan/komponen lebih panjang.

d) Waktu perbaikan relative cepat

2.Planed Maintenance: Kegiatan perawatan yang terencana dengan jadwal yang telah ditentukan oleh producen pembuat komponen,dimana setiap komponen mempunyai karakteritik yang berbeda,adapun cirinya yaitu:

a) Umur komponen sesuai ketentuan dari pabrik, pemakaian relatif panjang.

b) Beaya perawatan relatif murah.

c) Waktu perawatan cepat,karena tersedia suku cadang sebelumnya

3.Preventif Maintenance:Kegiatan pemeliharaan untuk meminimalisasi kerusa kan,dengan melakukan inspeksi secara rutin agar kerusakannya dapat diketahui lebih awal,karena jika dibiarkan dapat berakibat pada yang lain dengan ciri yaitu:

a) Biaya perawatan relative kecil,karena kondisi mesin seperti baru

b) Suku cadang selalu tersedia.

c) Waktu perawatan relarive cepat.

d) Kerusakan yang terjadi tidak fatal.

e) Kegiatan bersifat menjemukan(rutinitas).

f) Penggantian Suku cadang dipersiapkan sebelum kerusakan terjadi.

g) Memerlukan tenaga ahli (SDM) yang berpengalaman

Paparan diatas bisa disimpulkan bahwa ada 8 variabel yaitu :Cost, Availability, SDM, Reliability, Safety, Operasional, Jumlah dan Jenis Kapal, serta Karakteristik kapal. Pemilihan 3 variabel yang berpengaruh dari kedelapan variabel tersebut dilaksanakan secara kuisioner yang bisa digunakan dalam manajemen perawatan kapal- kapal militer.

\section{RESEARCH METHODS}

Dalam menentukan variabel- variabel penentu perawatan dimulai dari 8 variabel perawatan dibuatkan kuisioner terhadap pemilihan manajemen perawatan yang telah digunakan dalam perawatan kapal-kapal militer, melalui penyebaran kuisioner sebanyak 30 orang ABK (Crew) terdiri dari Perwira, Bintara dan Tamtama telah memilih variabel penentu perawatan terha dap ke 8 untuk dipilih untuk menjadi variabel penentu perawatan.

Dalam kegiatan Survey yang dilaksanakan di Pangkalan Kapal-kapal Militer di Batalion Perbekalan Angkutan Militer di Tanjung Priok,telah dikumpulkan 30 orang terdiri dari kelompok Perwira Pertama, Kelompok Bintara maupun Kelompok Tamtama untuk menentukan/memilih 8 Variabel penentu perawatan melalui kuisioner yang telah diberikan, ternyata dari 8 variabel yang terpilih adalah 6(enam) variabel dan selanjutnya keenam inilah yang dijadikan variabel penentu perawatan untuk dipilih. 


\subsection{ANALYTIC HIERARCHY PROCESS (AHP)}

Metode AHP merupakan salah satu bentuk metode pengambilan keputusan yang komprehensif, dan Memperhitungkan hal-hal yang bersifat kuantitatif dan kualitatif sekaligus. Model AHP memakai persepsi manusia yang dianggap ahli sebagai input utamanya. AHP bersifat sederhana, fleksibel serta menampung kreatifitas dalam rancangannya untuk memecahkan suatu masalah yang kompleks (Saaty,1986).

AHP dikembangkan oleh Saaty dan dipergunakan untuk menyelesaikan permasalahan yang komplek atau tidak berkerangka dimana data dan informasi statistik dari masalah yang dihadapi sangat sedikit. Secara umum hirarki dapat dibedakan menjadi dua jenis yaitu:

a. Hirarki struktural, yaitu masalah yang kompleks diuraikan menjadi bagian-bagiannya atau elemen-elemennya menurut ciri atau besaran tertentu. Hirarki ini erat kaitannya dengan menganalisa masalah yang kompleks melalui pembagian obyek yang diamati menjadi kelompok-kelompok yang lebih kecil.

b. Hirarki fungsional, menguraikan masalah yang kompleks menjadi bagian-bagiannya sesuai hubungan esensialnya. Hirarki ini membantu mengatasi masalah atau mempengaruhi sistem yang kompleks untuk mencapai tujuan yang diinginkannya seperti penentuan prioritas tindakan, alokasi sumber daya. Konsistensi matriks yaitu inkonsitensi sebesar $10 \%$ ke bawah ialah tingkat

inkonsistensi yang masih bisa diterima.

Menurut Turban (2005), Analytical Hierarcy Process (AHP) adalah suatu metode analisis dan sintesis yang dapat membantu proses Pengambilan Keputusan. AHP merupakan alat pengambil keputusan yang powerful dan fleksibel, yang dapat

membantu dalam menetapkan prioritas-prioritas dan membuat keputusan di mana aspekaspek kualitatif dan kuantitatif terlibat dan keduanya harus dipertimbangkan. Dengan mereduksi faktor-faktor yang kompleks menjadi rangkaian "one on one comparisons" dan kemudian mensintesa hasil-hasilnya, maka AHP tidak hanyamembantu orang dalam memilih keputusan yang tepat, tetapi juga dapat memberikan pemikiran/alasan yang jelas dan tepat.

Tabel 1 Skala Penilaian Perbandingan Berpasangan

\begin{tabular}{|c|l|l|}
\hline $\begin{array}{l}\text { Intensitas } \\
\mathrm{n}\end{array}$ & Kepentinga \\
1 & Kederangan & $\begin{array}{l}\text { Penjelasan } \\
\text { Dua elemen mempunyai } \\
\text { pengaruh yang sama } \\
\text { besarnya terhadap tujuan }\end{array}$ \\
\hline 3 & Elemen yang satu sedikit lebih & $\begin{array}{l}\text { Pengalaman dan penilaian } \\
\text { sedikit menyokong satu } \\
\text { elemen dibanding elemen } \\
\text { lainnya }\end{array}$ \\
\hline 5 & penting dari pada elemen yang lainnya & $\begin{array}{l}\text { Pengalaman dan penilaian } \\
\text { sangat kuat menyokong }\end{array}$
\end{tabular}

Jurnal Kajian Teknik Mesin

Vol. 1 No. 2 


\begin{tabular}{|c|l|l|} 
& dari pada elemen yang lainnya & $\begin{array}{l}\text { satu elemen dibanding } \\
\text { elemen lainnya }\end{array}$ \\
\hline 7 & $\begin{array}{l}\text { Satu elemen yang lain jelas lebih } \\
\text { mutlak penting daripada elemen }\end{array}$ & $\begin{array}{l}\text { Satu elemen yang kuat } \\
\text { disokong dan dominan } \\
\text { terlihat dalam praktek. }\end{array}$ \\
\hline 9 & Satu elemen mutlak penting dari & $\begin{array}{l}\text { Bukti mendukung elemen } \\
\text { yang satu terhadap } \\
\text { elemen yang lain, memiliki } \\
\text { tingkat penegasan } \\
\text { tertinggi yang mungkin } \\
\text { terkuat }\end{array}$ \\
\hline $2,4,6,8$ & pada elemen lainnya & $\begin{array}{l}\text { Nilai ini diberikan bila ada } \\
\text { dua kompromi }\end{array}$ \\
\hline Kebalikan & $\begin{array}{l}\text { Jika untuk aktivitas i mendapatkan suatu } \\
\text { angka dibanding dengan aktivitas j, maka } \mathrm{j} \\
\text { mempunyai nilai kebalikannya dengan } \mathrm{i}\end{array}$ & \\
\hline
\end{tabular}

Sumber : Saaty, 1993

Antara aktivitas yang satu dengan yang lain pada proses hirarki analisis memakai model hirarkis yang terdiri dari satu tujuan, kriteria atau beberapa sub kriteria dan alternatif untuk setiap masalah. Dalam menentukan penilaian diantara alternatif- alternatif di bawah kriteria tertentu, maka digunakan perbandingan berpasangan (Tabel 1) dengan menggunakan skala tertentu agar dapat dihasilkan bobot dari masing-masing alternatif keputusan.

Pada formula matematis pada model AHP dilakukan dengan menggunakan suatu matriks. Misalnya dalam suatu subsistem operasi terdapat $n$ elemen operasi A1, A2,...,An, maka hasil perbandingan secara berpasangan elemen operasi tersebut akan membentuk matriks perbandingan yang mana nilai-nilai $\mathrm{Wi} / \mathrm{Wj}$ dengan $\mathrm{i} . \mathrm{j}=1,2, \ldots, \mathrm{n}$ didapat dari partisipan, yaitu orang-orang yang berkompeten dalam masalah yang dianalisis (I Gde AstawaDiputra,2009)

\subsection{LANGKAH-LANGKAH PENYELESAIAN AHP}

Beberapa langkah yang digunakan dalam penelitian seperti yang akan dipaparkan di bawah ini :

1) Menentukan jenis-jenis kriteria yang akan digunakan untuk penentu variabel perawatan kapal.

2) Menyusun kriteria-kriteria tersebut dalam bentuk matriks berpasangan seperti pada tabel di bawah ini.

Tabel 2. Matriks Berpasangan

\begin{tabular}{|c|c|c|c|c|}
\hline Kriteria & 1 & 2 & 3 & 4 \\
\hline 1 & $1 \mathrm{VS} 1$ & $1 \mathrm{VS} 2$ & $1 \mathrm{VS} \mathrm{3}$ & 1 VS 4 \\
\hline 2 & $2 \mathrm{VS} 1$ & $2 \mathrm{VS} 2$ & 2 VB 3 & 2 VS 4 \\
\hline
\end{tabular}




\begin{tabular}{|l|l|l|l|l|}
3 & 3 VS 1 & 3 VS 2 & 3 VS 3 & 3 VS 4 \\
\hline 4 & 4 VS 1 & 4 VS 2 & 4 VS 3 & 4 VS 4 \\
\hline
\end{tabular}

3) Menjumlah matriks kolom.

4) Menghitung nilai elemen kolom krite ria dengan rumus masing-masing elemen kolom dibagi dengan jumlah matriks kolom.

5) Menghitung nilai prioritas kriteria dengan rumus menjumlah matriks baris hasil langkah ke 4 dan hasilnya 5 dibagi dengan jumlah kriteria.

6) Menentukan alternatif-alternatif yang akan menjadi pilihan.

7) Menyusun alternatif-alternatif yang telah ditentukan dalam bentuk matriks berpasangan untuk masing-masing kriteria. Sehingga akan ada sebanyak $n$ buah matriks berpasangan antar alternatif.

8) Masing- masing matriks berpasangan antar alternatif sebanyak $n$ buah matriks, masingmasing matriksnya dijumlah per kolomnya.

9) Menghitung nilai prioritas alternatif masing-masing matriks berpasangan antar alternatif dengan rumus seperti langkah 4 dan langkah 5 .

10) Menguji konsistensi setiap matriks berpasangan antar alternatif dengan rumus masingmasing elemen matriks berpasangan pada langkah 2 dikalikan dengan nilai prioritas kriteria.

Hasilnya masing-masing baris dijumlah, kemudian hasilnya dibagi dengan masingmasing nilai prioritas kriteria sebanyak $\mathrm{n}$ :

$\alpha_{1} \alpha_{2} \alpha_{3} \alpha_{4} \alpha_{5} \ldots \alpha_{n}$

dimana $\alpha_{\mathrm{n}}=$ nilai prioritas ke $\mathrm{n}$

11) Menghitung Lamda max dengan rumus

$\alpha_{\max }=\sum \alpha * 1 / \mathrm{n}$

12) Menghitung CI

$\mathrm{CI}=\alpha_{\max } *(1 /(\mathrm{n}-1))$

13) Menghitung $\mathrm{CR}$ dengan rumus

$\mathrm{CR}=\mathrm{CI}^{*} 1 / \mathrm{RC}$

- Dimana CR adalah nilai tabel Saaty Jika CR $<0,1$ maka nilai perbandingan berpasangan pada matriks kriteria yang diberikan konsisten.

- Jika CR > 01, maka maka nilai perbandingan berpasangan pada matriks kriteria yang diberikan tidak konsisten.

- Sehingga jika tidak konsisten, maka pengisian nilai-nilai pada matriks berpasangan pada unsur kriteria maupun alternatif harus diulang.

Tabel 2. Tabel Index Ratio

\begin{tabular}{|l|r|r|r|r|r|r|r|r|}
\hline $\mathrm{n}$ & 3 & 4 & 5 & 6 & 7 & 8 & 9 & 10 \\
\hline $\mathrm{RI}$ & 1 & 1 & 1.12 & 1.2 & 1.32 & 1.41 & 1.45 & 1.49 \\
\hline
\end{tabular}

14) Menyusun matriks baris antara alternatif versus kriteria yang isinya hasil perhitungan proses langkah 7, langkah 8 dan langkah 9.

15) Hasil akhirnya berupa prioritas global sebagai nilai yang digunakan oleh pengambil keputusan berdasarkan skor yang tertinggi.

\section{VARIAB EL PENENTU PERAWATAN KAPAL}

Jurnal Kajian Teknik Mesin

Vol. 1 No. 2 
Pengolahan data yang dilakukan menggunakan Expert Choice sesuai dengan kusioner yang diedarkan pada 30 crew kapal menghasilkan prioritas variabel perawatan mesin kapal. Hasilnya bisa dilihat pada gambar 1.

Prosentase tertinggi didapat oleh HRD dengan nilai $0.246,0.244$ dan 0.242 . Ini bisa diartikan bahwa ada $25 \%$ crew kapal yakin perawatan kapal sangat tergantung pada HRD atau kemampuan dan kesiapan tenaga maintenance kapal yang ada. Prioritas kedua dipengaruhi oleh COST yaitu $0.223,0.222$ dan 0.220 . ini bisa diartikan bahwa biaya atau bud get maintenance kapal juga berpengaruh secara signifikan untuk perawatan kapal. $22 \%$ responden menjawab hal yang sama.

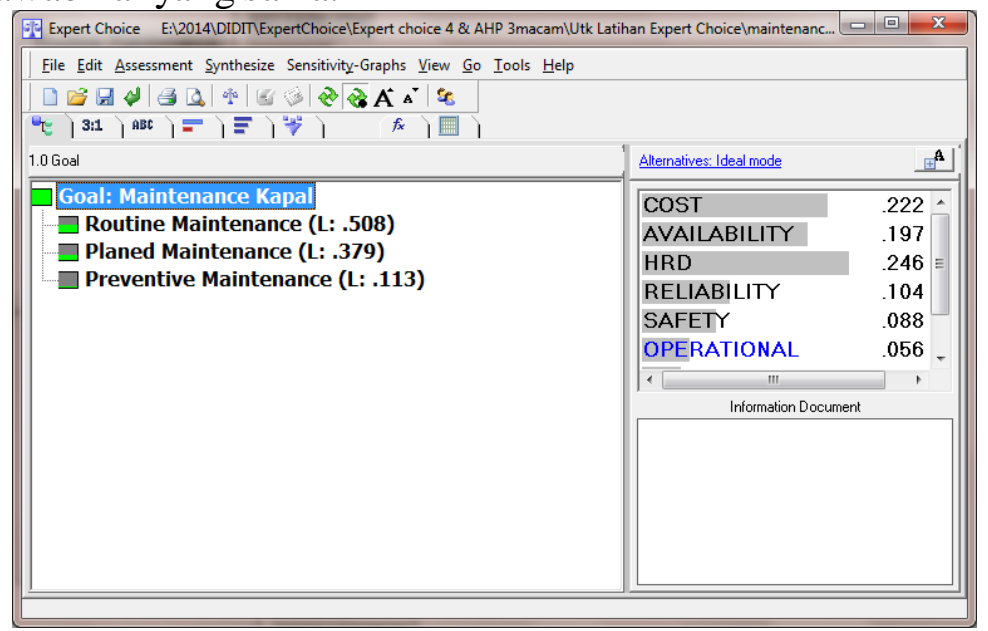

Gambar 1. Hasil Goal Maintenance

Berdasarkan perhitungan GOAL didapatkan 50.8\% responden percaya bahwa tipe perawatan kapal yang berpengaruh terhadapa kelayakan dan kesiapan kapal untuk stand by atau dipakai adalah Routine Maintenance. Sementara untuk Planed Maintenance hanya $37.9 \%$ dan Preventive Maintenance hanya 11.3\%. Bisa dilihat pada gambar 2 diatas.

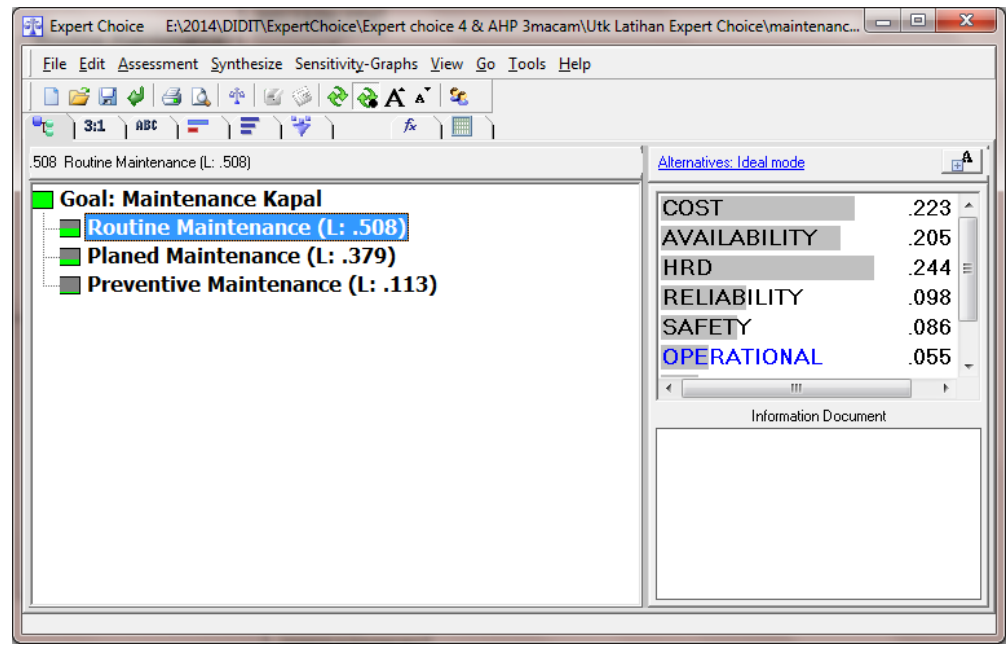

Gambar 2.Hasil Routine Maintenance

Jurnal Kajian Teknik Mesin

Vol. 1 No. 2 
Berdasarkan perhitungan ROUTINE MAINTENANCE didapatkan $24.4 \%$ responden percaya bahwa variabel HRD yang sangat berpengaruh terhadap perawatan kapal. Cost $22.3 \%$ dan Avilability 20.6\%. Bisa dilihat pada gambar 2 diatas.

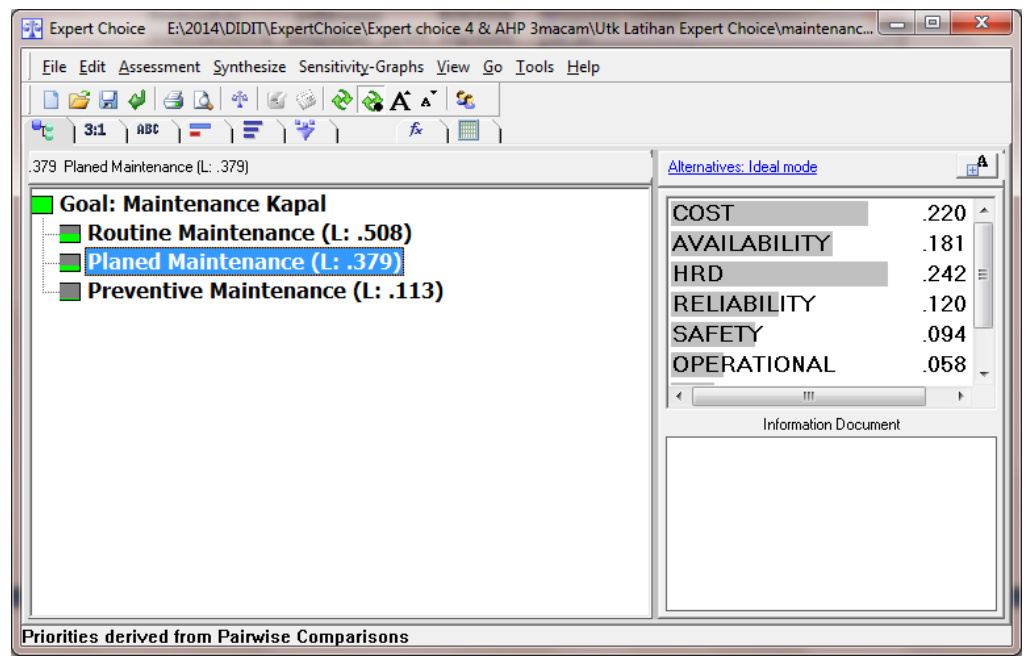

Gambar 3.Hasil Planed Maintenance

Berdasarkan perhitungan PLANNED MAINTENANCE didapatkan 24.2\% responden percaya bahwa variabel HRD yang sangat berpengaruh terhadap peraw atan kapal. Cost $22.0 \%$ dan Avilability $18.1 \%$. Bisa dilihat pada gambar 3 diatas.

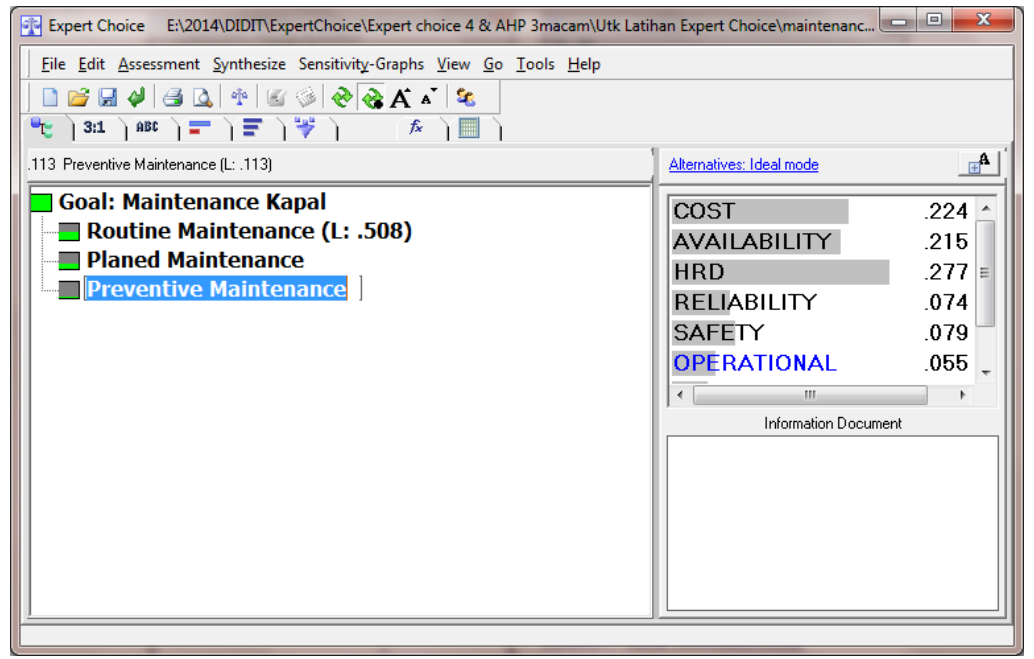

Gambar 4.Hasil Preventive Maintenance

Berdasarkan perhitungan PREVENTIVE MAINTENANCE didapatkan 27.7\% responden percaya bahwa variabel HRD yang sangat berpengaruh terhadap peraw atan kapal. Cost $22.4 \%$ dan Avilability 21.5\%. Bisa dilihat pada gambar 4 diatas.

Jurnal Kajian Teknik Mesin

Vol. 1 No. 2 


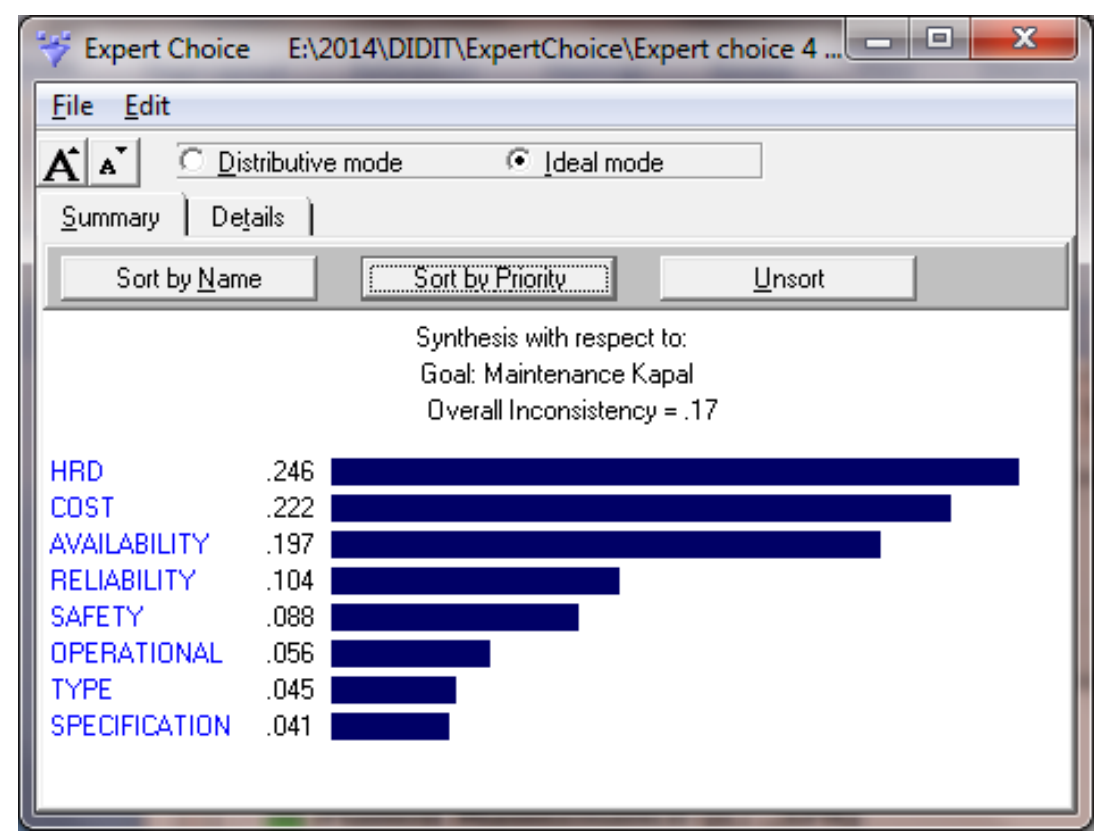

Gambar 5. Grafik Ideal Mode

Berdasarkan perhitungan RESPECT TO GOAL didapatkan 24.6\% responden percaya bahwa variabel HRD yang sangat berpengaruh terhadap perawatan kapal. Cost $22.2 \%$ dan Avilability $19.7 \%$. Bisa dilihat pada gambar 5 diatas.

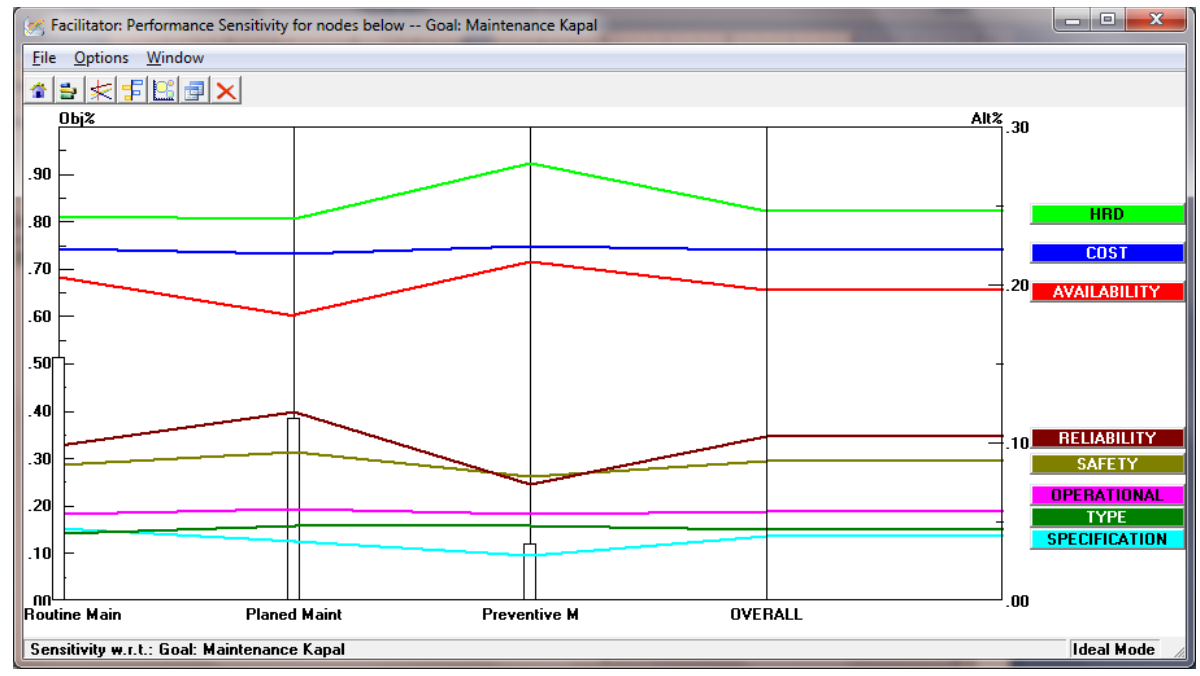

Gambar 7. Grafik Performance Sensitivity

Analisis dari grafik Performance Sensitifity adalah bahwa kecenderungan COST tidak banyak berubah dalam semua kondisi perawatan. Variabel Availability terendah berada pada Planed Maintenance. Untuk HRD nilai tertinggi pada Preventive Maintenance.

Hasil secara keseluruhan diperlihatkan oleh gambar 8 di bawah ini :

Jurnal Kajian Teknik Mesin

Vol. 1 No. 2 


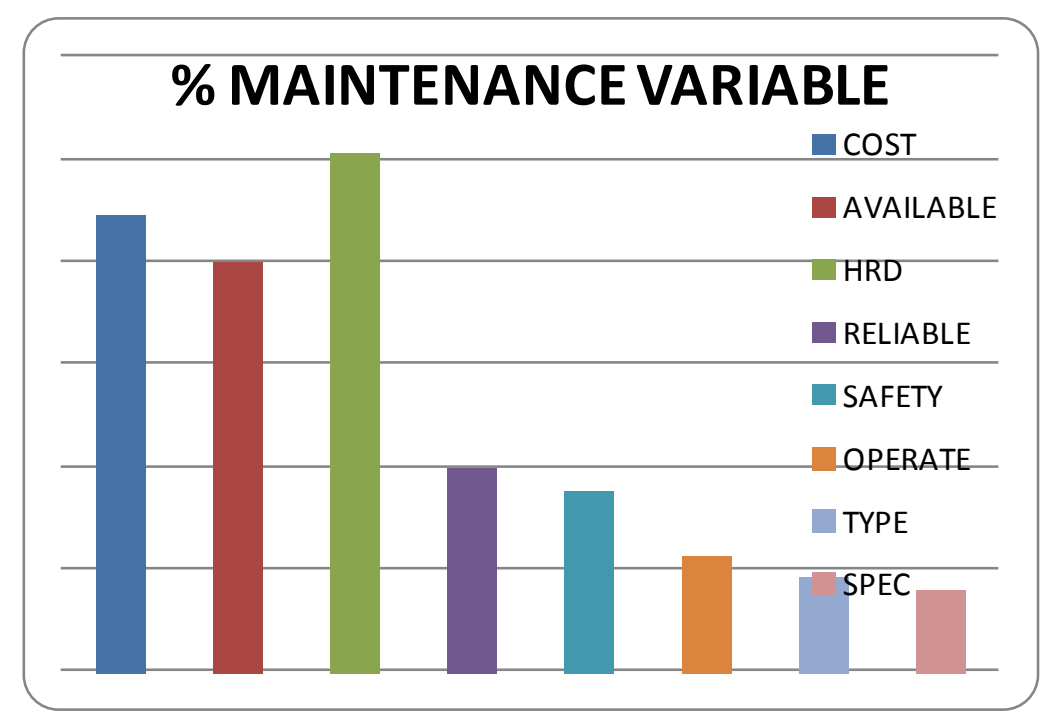

Gambar 8. Grafik Variable Maintenance

Peringkat variabel untuk perawatan permesinan kapal di TNI AD adalah HRD $=25 \%$, $\operatorname{COST}=23 \%$ dan Availability $=20 \%$. Berarti ada 7-8 orang yang mengasumsikan bahwa perawatan kapal sangat dipengaruhi oleh kemampuan dan ketersediaan SDM yang dimiliki oleh TNI AD.

\section{CONCLUSION}

Dari studi pemilihan ini yang didasarkan pada output dari Expert Choice 11 didapatkan bahwa faktor terpenting untuk perawatan kapal dalam rangka meningkatkan keandalan sebuah kapal adalah tersedianya SDM, Biaya dan Availability.

\section{REFERENCES}

[1] Artana, K.B., 2003. A Research on Marine Machinery Selection Using Hybrid Method of Generalized Reduced Gradient and Decision Matrix, Dis sertation, Kobe University of Mercantile Marine Japan.

[2] Jacquet, L.E., Siskos, J., 1982. Assessing a Set of Additive Utility Functions for Multiple Criteria Decision Making: The UTA Method.European Journal of Operation Research, Vol. 10, p.151-164.

[3] Jian, B.Y., 1995. Multiple Criteria Decision Making in Design Selection and Synthesis.Journal of Engineering Design, Vol. 6, No. 3, p. 207-229.

[4] Sen, P., 1994. A General Multi-Level Evaluation Process for Hybrid MADM. IEEE Transaction, Vol. 24, No. 10, p. 688-695.

[5] Source Stap Operasi Panglima Armada timur 2011.

[6] Thomas L. Saaty and Luis G Vargas 2006 “ Decision Making with the Analytic Network Process" Economic, Political, Social and Technological, Applied with Benefits, Opportunities Costs and Risks.

[7] UNCLOS 1982 (Undang- undang Nomor 17 Tahun 1985 tentang pengesahan United Nations Convention on the Low of the Sea). 